Original article

\title{
Prevalence and determinants of Vitamin A deficiency among children in India: Findings from a national cross-sectional survey
}

\author{
Sampurna Kundu, Balram Rai *, Anandi Shukla \\ Department of Mathematical Demography and Statistics, International Institute for Population Sciences, Mumbai, India
}

\section{A R T I C L E I N F O}

\section{Keywords:}

Vitamin A deficiency

Micronutrient

Under five children

India

Nutrition

\begin{abstract}
A B S T R A C T
Background: Vitamin A deficiency is major concern especially for the children living in developing countries. According to UNICEF around one third of the children are not receiving the supplementation of Vitamin A they need.

Aim: The present study focuses on Vitamin A deficiency among the children aged 12-59 months in India by analysing the data from the latest nutritional survey.

Methods: The Comprehensive National Nutrition Survey (CNNS), conducted during 2016-18, dataset for 0-5 years age has been used in the study. The study has employed bi-variate analysis to assess the prevalence of Vitamin A deficiency (VAD) based on the CRP (C-reactive protein) values (CRP $\leq 5 \mathrm{mg} / \mathrm{L}$ ), by the different socioeconomic and demographic characteristics along with dietary diversity, stunting, anaemia and breastfeeding related variables. Log-binomial regression model has been used for the multivariable analysis and based on that predicted probabilities were computed.

Results: The overall prevalence of VAD in India is $17.54 \%$. Children who are exposed to longer duration of breastfeeding have lower prevalence of VAD. Children in poorer economic sections are more vitamin A deficient compared to children in richer economic sections. The prevalence of VAD among children having minimum diet diversity is $18.63 \%$.

Conclusion: The study suggests in focusing on the targeted groups of children who are at more risk in developing VAD and planning interventions for specific groups. The nutrition programs require a multisectoral approach for addressing the needs of macronutrient and micronutrient deficiencies simultaneously to enhance the current situation of nutrition among children in India.
\end{abstract}

\section{Introduction}

Nutrition is an indispensable part of human life, which is inevitable for leading a healthy life. Nutrients are usually categorized into macronutrients and micronutrients. Macronutrients are those nutrients, which body needs in large amounts including Fats, Proteins, and Carbohydrates. Micronutrients are needed in smaller amounts, which includes several vitamins and minerals. The quantity of micronutrientsvitamins and minerals required in a balance diet are very low yet they have a profound impact on the physical and mental growth of the child. Vitamin A deficiency is major concern especially for the children living in developing countries. Vitamin A is necessary for the regulation of various bodily functions such as growth, vision, reproduction, morphogenesis, immunity etc. hence in broader sense, it plays an important role in process like cellular differentiation and functions. The vitamin A deficiency may lead to various health issues such as susceptibility to various infections, stunting, eye health, and vision issues. ${ }^{1,2}$ $\mathrm{VAD}$ also affects the systematic immunity and results in various infections with increased severity. ${ }^{3}$ Vitamin A plays a major role in various biological phenomenon and it can't be produced naturally in human body, hence it must be consumed via diet resources. ${ }^{4}$ VAD among children is also associated with increased child mortality mainly due to detrimental effects on the immune system. ${ }^{5}$ According to a report from UNICEF, vitamin A can increase child's chance of survival by 12-24 percent $^{6}$

According to UNICEF, around one third of the children are not receiving the supplementation of Vitamin A they need. ${ }^{7}$ According to WHO guideline, ${ }^{8}$ approximately 190 million pre-school children are affected by VAD (i.e., serum retinol less than $0.70 \mu \mathrm{mol} / \mathrm{L}$ ), majority of them belongs to Africa and South-east Asia region of WHO. World bank

\footnotetext{
* Corresponding author.

E-mail address: balram03@iipsindia.ac.in (B. Rai).
} 
stated that the vitamin A supplementation is a cost-effective measure to improve child survival in pre-school children. ${ }^{9}$ Around 650,00 early childhood deaths from diarrhea, measles, malaria and other infections each year be contributed to VAD as an underlying cause. ${ }^{2}$ The risk of death among children given small weekly dose of Vitamin A was less than half than in control group in a randomized controlled study conducted in south India. ${ }^{10}$ VAD is associated with various poor social, economic and ecological conditions. Deprived children who are not able to get proper diet are usually exposed to VAD at a very early age. Such deficiency will also reflect in the later stages of life for example during the reproductive age, a female who has earlier suffered from VAD and stays chronically deficient will have its impact on her various life events. ${ }^{11}$ Vitamin A has a significant role to play in human immune function hence its also called anti-infectious vitamin. ${ }^{12}$ Children who suffer from VAD has a chance to get infection easily and this infection make their vitamin A status lower, thus making it a vicious cycle.

Malnutrition among the children is still a challenge for India and hindrance in achieving the sustainable development goals for health in India. India is leading among its neighboring countries in terms of magnitude of clinical and subclinical VAD among young children. ${ }^{13}$ According to National Nutrition Monitoring Bureau (NNMB) Survey, around $62 \%$ of the preschool children in India are found to suffer from $\mathrm{VAD}$ and $21.5 \%$ have a low serum retinol levels $<0.35 \mu \mathrm{mol} / \mathrm{l}$. According to UNICEF, only $56 \%$ of the children $6-59$ months received two-dose VAS coverage in India. ${ }^{14}$ National Family Health Survey 2015-16 revealed that around $60 \%$ of the children age 6-59 months received Vitamin A supplementation and 44\% children aged 6-23 months have taken Vitamin A enriched food. This coverage varied according to various socio economic and demographic characteristics. ${ }^{15}$ There is a scarcity of studies specially focusing on micronutrient deficiency among Indian children, hence there is need for studies exploring the specific micronutrient deficiencies among children.

The present study focuses on Vitamin A deficiency among the children aged 12-59 months in India by analysing the data from the latest nutritional survey. The primary objective of the study is to estimate the Vitamin A deficiency among children across various socio-economic and demographic strata existing in India. This will help us in assessing the current scenario of $\mathrm{VAD}$ in India and the heterogeneity of the prevalence among children belonging to several groups. The second objective of the study is to examine the various factors associated with VAD and its determinants. This study will help us in prioritizing the groups for vitamin A supplementation and planning the focused interventions for those groups, which can finally lead towards improvement of the current situation of malnutrition among Indian children.

\section{Data and methods}

The data used to fulfil the objectives of the study is the Comprehensive National Nutrition Survey (CNNS), conducted during 2016-18, under the supervision of the Ministry of Health and Family Welfare, in collaboration with Population Council and UNICEF. The survey provides a comprehensive nutrition profile of the national representative sample of children of 0-4 years, school children of 5-9 years and adolescents of 10-19 years age, based on biological sample assessment and various anthropometric measures. The sampling procedure adopted for the CNNS survey was a stratified multi-stage probability proportional to size cluster sampling design, in order to selected national samples of households and individuals across India in the age group 0-19 years. The survey has utilized gold standard methods for the assessment of anaemia, micronutrient deficiencies like iron, zinc, vitamin A, B12, iodine etc, and biomarkers for non-communicable diseases for the first time and indicators for malnutrition has also been measured. The survey interviewed 112,316 children and adolescents; collected 51,029 blood, stool and urine samples and 360 anthropometric measures. In the survey, Vitamin A Deficiency (VAD), has been measured by serum retinol concentration in blood, and following the WHO guidelines, the deficiency is defined by a cut off of $<20 \mu \mathrm{g} / \mathrm{dL}$. The C-reactive protein (CRP) has been adjusted, which is an inflammatory biomarker. The CRP was measured by two methods- Nephelometry and Particle-enhanced immunonephelometry, whereas serum retinol concentration was measured by High-performance Liquid Chromatography (HPLC) Reverse phase chromatography. For CRP, the nephelometry method had a lower limit of quantitation (LLOQ) for serum CRP of $3 \mathrm{mg} / \mathrm{L}$, whereas the particle-enhanced immunonephelometry was a high-resolution method with a LLOQ for serum CRP of $0.2 \mathrm{mg} / \mathrm{L}$. The All cases with CRP $>5 \mathrm{mg} / \mathrm{L}$ has been excluded from the analysis. ${ }^{16}$

The present study utilizes the data for the age group $0-4$ years, with a total sample of 38,060, to measure the Vitamin A deficiency (VAD) among them according to several socio-economic and determinant health factors. The socio-demographic and economic variables consists of sex of child (male, female), age of child in months (12-17; 18-23; 24-35; 36-47; 48-59), mother's schooling (No schooling; less than 5 years schooling; 5-7 years; 8-9 years; $10-11$ years; more than 12 years), religion (Hindu; Muslims; Others), caste (Scheduled caste; Scheduled tribe; Other backward classes; Others), residence (urban, rural), wealth index (Poorest, poor, middle, rich, richest) and regions of India (North, Central, East, West, South, North-east). Among other determining factors taken are minimum dietary diversity, stunting, severe stunting, anaemia and duration of breast feeding.

The dietary diversity score has been computed by taking into consideration the 7 food groups, which are, grains, roots and tubers; legumes and nuts; dairy products; fish and meat; eggs; vitamin A rich food; and, other fruits and vegetables. The consumption of minimum 4 food groups was coded as having minimum diet diversity. The children whose height for age Z-score is less than minus two standard deviations (-2SD) from the median of the reference population as recommended by the world health organization (WHO) are considered as short for age, that is, stunted and children whose height for age Z-score less than minus three standard deviation (-3SD) from the median of the reference population are considered as severely stunted. The child has been breastfed or not, the duration of breastfeeding in months $(0-5 ; 6-11$; $12+$ ), child given anything else except breast milk in first 3days or not and child has anaemia or not, are some of the other covariates considered for the study.

The study has employed bi-variate analysis to assess the prevalence of Vitamin A deficiency (VAD) based on the CRP (C-reactive protein) values (CRP $\leq 5 \mathrm{mg} / \mathrm{L}$ ), by the different socio-economic and demographic variables along with dietary diversity, stunting, anaemia and breastfeeding related variables. The Chi-square test was used to determine if there is significant association between VAD and the covariates, and Cramer's V to determine the strength of association. From the GLM framework, the log-binomial regression model (GLM-Bin) has been used for the multivariate analysis and the resulting estimated relative risks are utilized for the interpretation. In the log-binomial regression model, the conditional distribution of the outcome variable given the predictor variables is binomial with mean response related to the predictors by link function $\log (\mathrm{pi})$, and the probability of the outcome variable (VAD), assume that the error terms have a binomial distribution. ${ }^{17}$ Consider $Y_{i}$ as the observed binary outcome, that is, $\mathrm{VAD}$, for the ith individual and $x_{i}$ 's are the covariates, the equation is given by

$\log \left(p_{i}(\beta)\right)=x_{i}^{T} \beta$

where. $p_{i}(\beta)=P\left(y_{i}=1 \mid x_{i}\right), o \leq p_{i} \leq 1$

The predicted values for the outcome variable are obtained after the model estimation, which further gives the predicted VAD prevalence adjusted according to the covariates. STATA 14 and ArcGIS software has been used for the analysis. 


\section{Results}

\subsection{Prevalence of Vitamin A deficiency (VAD)}

Table 1 represents the prevalence of VAD among various sociodemographic factors and factors related to child's nutritional status. The overall prevalence of VAD in India is $17.54 \%$. The highest prevalence of VAD is in the northeast region (19.56\%), while the lowest in west region (11.42\%). Fig. 1 provides the prevalence of VAD in all the Indian states. The vitamin A deficiency in male and female children are almost equal. Children in age group 36-47 months have the highest prevalence of $\mathrm{VAD}$, while children in age group 18-23 months have the lowest prevalence. The prevalence of VAD decreases with increase in mother's years of education. Children belonging to SC caste category have the highest prevalence of VAD i.e. $20.63 \%$ compared to other categories of caste. Children in poorer economic sections are more vitamin A deficient compared to children in richer economic sections. The prevalence of VAD among children having minimum diet diversity is $18.63 \%$. Children who are exposed to longer duration of breastfeeding have lower prevalence of VAD. Stunted and severely stunted children have higher prevalence of VAD compared to non-stunted children. Anaemic children also have higher prevalence of VAD compared to nonanaemic children.

\subsection{Determinants of Vitamin A deficiency}

Table 2 provides the adjusted relative risk from log binomial regression model of VAD on all the background variables. The adjusted relative risk of having VAD among females is $0.935(0.845,1.035)$ compared to male children, indicating the risk of having VAD is nearly equal among male and female children. The adjusted relative risk of VAD increases with the increment in age of the children. The risk of VAD among children whose mothers have more than 12 years of education is $0.682(0.566,0.822)$ times less compared to mothers having no schooling. Children residing in urban area have higher risk of having VAD compared to children in rural area. Children belonging to richer

Table 1

Prevalence of VAD by background variables and results for tests of association.

\begin{tabular}{|c|c|c|c|c|c|}
\hline Background variables & & $\begin{array}{l}\text { Vitamin A Deficiency (VAD) } \\
\%\end{array}$ & $\begin{array}{l}\text { Weighted } \\
\text { Sample }\end{array}$ & $\begin{array}{l}\text { p-value of Chi-square } \\
\text { test }\end{array}$ & Cramer's V \\
\hline \multirow[t]{2}{*}{ Sex of Child } & Male & 17.81 & 700 & 0.082 & -0.020 \\
\hline & Female & 17.23 & 609 & & \\
\hline \multirow[t]{5}{*}{ Age of Child (in months) } & $12-17$ & 19.83 & 98 & 0.262 & 0.027 \\
\hline & $18-23$ & 12.47 & 82 & & \\
\hline & $24-35$ & 14.54 & 245 & & \\
\hline & $36-47$ & 20.82 & 452 & & \\
\hline & $48-59$ & 17.59 & 431 & & \\
\hline \multirow[t]{6}{*}{ Mother's Schooling } & No schooling & 22.91 & 492 & 0.000 & 0.109 \\
\hline & $<5$ years completed & 14.17 & 64 & & \\
\hline & 5-7 years completed & 16.44 & 202 & & \\
\hline & 8-9 years completed & 19.55 & 258 & & \\
\hline & $\begin{array}{l}10-11 \text { years } \\
\text { completed }\end{array}$ & 14.28 & 175 & & \\
\hline & $\geq 12$ years completed & 12.61 & 227 & & \\
\hline \multirow[t]{3}{*}{ Religion } & Hindu & 19.00 & 1133 & 0.357 & 0.017 \\
\hline & Muslim & 9.18 & 105 & & \\
\hline & Others & 19.96 & 71 & & \\
\hline \multirow[t]{4}{*}{ Caste } & SC & 20.63 & 388 & 0.000 & 0.073 \\
\hline & ST & 17.18 & 133 & & \\
\hline & OBC & 18.89 & 578 & & \\
\hline & Others & 12.01 & 210 & & \\
\hline \multirow[t]{2}{*}{ Residence } & Rural & 17.76 & 997 & 0.262 & -0.013 \\
\hline & Urban & 16.86 & 312 & & \\
\hline \multirow[t]{5}{*}{ Wealth index } & Poorest & 26.32 & 300 & 0.000 & 0.111 \\
\hline & Poor & 17.80 & 268 & & \\
\hline & Middle & 18.19 & 311 & & \\
\hline & Rich & 16.61 & 266 & & \\
\hline & Richest & 10.90 & 165 & & \\
\hline \multirow[t]{6}{*}{ Regions } & North & 14.55 & 111 & 0.000 & 0.077 \\
\hline & Central & 18.92 & 370 & & \\
\hline & East & 19.22 & 451 & & \\
\hline & West & 11.42 & 46 & & \\
\hline & South & 16.14 & 280 & & \\
\hline & North-East & 19.56 & 52 & & \\
\hline \multirow[t]{2}{*}{ Has Minimum Diet Diversity } & No & 16.40 & 807 & 0.001 & -0.040 \\
\hline & Yes & 18.63 & 424 & & \\
\hline \multirow[t]{2}{*}{ Ever been breastfed } & No & 16.41 & 63 & 0.003 & 0.034 \\
\hline & Yes & 17.60 & 1246 & & \\
\hline \multirow{2}{*}{$\begin{array}{l}\text { Child given anything other than breastmilk in the first } 3 \\
\text { days }\end{array}$} & No & 16.51 & 855 & 0.004 & 0.035 \\
\hline & Yes & 20.86 & 361 & & \\
\hline \multirow[t]{3}{*}{ Duration of exclusive breastfeeding (in months) } & $0-5$ & 19.14 & 341 & 0.000 & 0.085 \\
\hline & $6-11$ & 19.00 & 709 & & \\
\hline & $12+$ & 11.83 & 164 & & \\
\hline \multirow[t]{2}{*}{ Stunted } & No & 17.41 & 836 & 0.000 & 0.044 \\
\hline & Yes & 18.24 & 453 & & \\
\hline \multirow[t]{2}{*}{ Severely Stunted } & No & 17.36 & 1168 & 0.001 & 0.039 \\
\hline & Yes & 21.72 & 121 & & \\
\hline \multirow[t]{2}{*}{ Anaemic } & No & 16.10 & 636 & 0.000 & 0.049 \\
\hline & Yes & 20.66 & 534 & & \\
\hline Sample & & 17.54 & 1309 & & \\
\hline
\end{tabular}




\section{Prevalence of Vitamin $A$ Deficiency \\ Among under five children, CNNS, $2016-18$}

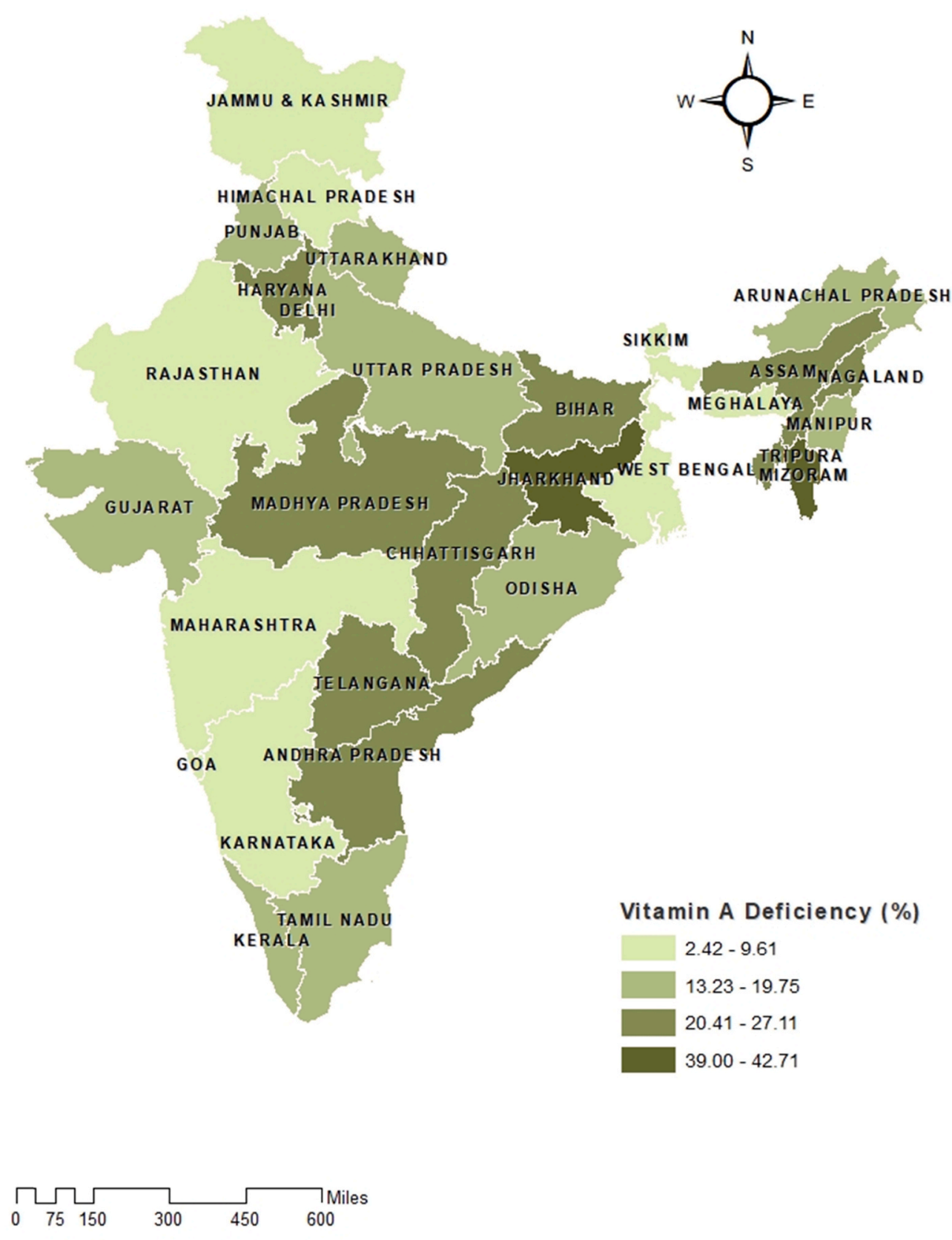

Fig. 1. Prevalence of VAD among the Indian states.

wealth index have low lower risk of developing VAD compared to children belonging to poorer wealth index. The longer duration of breastfeeding has a significant effect on having lower risk VAD among children. The risk of VAD in anaemic children is $1.26(1.13,1.41)$ times higher than non-anaemic children. The severely stunted children have a $1.16(0.95,1.43)$ times higher risk of having VAD compared to not severely stunted children.

Table 3 provides the predicted prevalence of VAD from the log binomial regression model for all the variables. The predicted prevalence of VAD after adjusting for other covariates used in the analysis among female children is $19.66 \%$ compared to $18.69 \%$ among male children. The highest predicted prevalence of VAD is for the children of age group 36-47 months and lowest for the age group 24-35 months. Children belonging to ST caste have the highest predicted prevalence of VAD. Children belonging to poorest wealth quantile have the highest predicted prevalence of $\mathrm{VAD}$, while children belonging to rich wealth quantile have the lowest predicted prevalence. The predicted prevalence of VAD decreases with the increase in mother's years of education. The highest predicted prevalence of VAD is found in central region in contrast to the northeast region, which had the highest VAD prevalence without adjusting for the covariates. The adjusted prevalence of VAD among the children having minimum diet diversity is 17.91 compared to 
Table 2

Adjusted Relative Risk with 95\% CI from Log Binomial Regression Model for VAD by background variables.

\begin{tabular}{|c|c|c|}
\hline \multicolumn{2}{|l|}{ Outcome Variable: VAD } & \multirow{2}{*}{$\begin{array}{l}\text { Adjusted Relative } \\
\text { Risk }\end{array}$} \\
\hline Sex of Child & Male ${ }^{\circledR}$ & \\
\hline & Female & $\begin{array}{l}0.935 \\
(0.845,1.035)\end{array}$ \\
\hline \multirow[t]{5}{*}{ Age of Child (in months) } & $12-17 \AA$ & \\
\hline & $18-23$ & $\begin{array}{l}0.972 \\
(0.754,1.252)\end{array}$ \\
\hline & $24-35$ & $0.889(0.712,1.11)$ \\
\hline & $36-47$ & $\begin{array}{l}1.069 \\
(0.862,1.325)\end{array}$ \\
\hline & $48-59$ & $\begin{array}{l}1.103 \\
(0.889,1.369)\end{array}$ \\
\hline \multirow[t]{9}{*}{ Mother's Schooling } & No schooling ${ }^{\circledR}$ & \\
\hline & $\begin{array}{l}<5 \text { years } \\
\text { completed }\end{array}$ & $\begin{array}{l}0.835 \\
(0.665,1.049)\end{array}$ \\
\hline & 5-7 years & 0.891 \\
\hline & completed & $(0.754,1.053)$ \\
\hline & $\begin{array}{l}8-9 \text { years } \\
\text { completed }\end{array}$ & $0.884(0.751,1.04)$ \\
\hline & 10-11 years & $0.719^{* * *}$ \\
\hline & completed & $(0.592,0.872)$ \\
\hline & $\geq 12$ years & $0.682^{* * *}$ \\
\hline & completed & $(0.566,0.822)$ \\
\hline \multirow[t]{3}{*}{ Religion } & Hindu $(\mathbb{R}$ & \\
\hline & Muslim & $\begin{array}{l}0.937 \\
(0.788,1.114)\end{array}$ \\
\hline & Others & $\begin{array}{l}1.217^{* * *} \\
(1.035,1.432)\end{array}$ \\
\hline \multirow[t]{4}{*}{ Caste } & $\mathrm{SC}(\mathbb{R}$ & \\
\hline & ST & $\begin{array}{l}1.031 \\
(0.862,1.232)\end{array}$ \\
\hline & OBC & $\begin{array}{l}1.082 \\
(0.937,1.249)\end{array}$ \\
\hline & Others & $\begin{array}{l}0.814 * * * \\
(0.692,0.956)\end{array}$ \\
\hline \multirow[t]{2}{*}{ Residence } & Rural ${ }^{\circledR}$ & \\
\hline & Urban & $\begin{array}{l}1.186^{* * *} \\
(1.059,1.329)\end{array}$ \\
\hline \multirow[t]{5}{*}{ Wealth index } & Poorest ${ }^{\circledR}$ & \\
\hline & Poor & $0.925(0.75,1.141)$ \\
\hline & Middle & $\begin{array}{l}0.972 \\
(0.793,1.192)\end{array}$ \\
\hline & Rich & $\begin{array}{l}0.793 * * * \\
(0.635,0.991)\end{array}$ \\
\hline & Richest & $0.828(0.65,1.056)$ \\
\hline \multirow[t]{6}{*}{ Regions } & North $\mathbb{R}$ & \\
\hline & Central & $\begin{array}{l}1.088 \\
(0.883,1.342)\end{array}$ \\
\hline & East & $\begin{array}{l}1.074 \\
(0.904,1.275)\end{array}$ \\
\hline & West & $\begin{array}{l}0.784 \\
(0.606,1.016)\end{array}$ \\
\hline & South & $0.995(0.825,1.2)$ \\
\hline & North-East & $1.04(0.854,1.266)$ \\
\hline \multirow[t]{2}{*}{ Has Minimum Diet Diversity } & $\mathrm{No} \otimes$ & \\
\hline & Yes & $\begin{array}{l}0.935 \\
(0.838,1.043)\end{array}$ \\
\hline \multirow{2}{*}{$\begin{array}{l}\text { Child given anything other than } \\
\text { breastmilk in the first } 3 \text { days }\end{array}$} & No ${ }^{\circledR}$ & \\
\hline & Yes & $\begin{array}{l}1.133^{* * *} \\
(1.005,1.278)\end{array}$ \\
\hline \multirow{3}{*}{$\begin{array}{l}\text { Duration of exclusive breastfeeding (in } \\
\text { months) }\end{array}$} & $0-5 \circledR$ & \\
\hline & $6-11$ & $\begin{array}{l}0.965 \\
(0.858,1.086)\end{array}$ \\
\hline & $12+$ & $\begin{array}{l}0.667^{* * *} \\
(0.569,0.781)\end{array}$ \\
\hline \multirow[t]{2}{*}{ Stunted } & No ${ }^{\circledR}$ & \\
\hline & Yes & $0.99(0.87,1.127)$ \\
\hline \multirow[t]{2}{*}{ Severely Stunted } & $\mathrm{No}{ }^{\circledR}$ & \\
\hline & Yes & $\begin{array}{l}1.165 \\
(0.948,1.433)\end{array}$ \\
\hline \multirow[t]{2}{*}{ Anaemic } & $\mathrm{No}(\mathbb{R}$ & \\
\hline & Yes & $\begin{array}{l}1.263^{* * *} \\
(1.131,1.41)\end{array}$ \\
\hline
\end{tabular}

(R) Reference Category; ***: 99\% significance level; **: 95\% significance level; *: $90 \%$ significance level.

Table 3

Predicted prevalence of VAD from log binomial regression model for background variables.

\begin{tabular}{|c|c|c|}
\hline \multicolumn{2}{|l|}{ Background variables } & \multirow{2}{*}{$\begin{array}{l}\text { Predicted VAD } \\
\% \\
19.668\end{array}$} \\
\hline Sex of Child & Male & \\
\hline & Female & 18.697 \\
\hline \multirow[t]{5}{*}{ Age of Child (in months) } & $12-17$ & 19.732 \\
\hline & $18-23$ & 19.057 \\
\hline & 24-35 & 16.900 \\
\hline & $36-47$ & 20.304 \\
\hline & $48-59$ & 19.787 \\
\hline \multirow[t]{6}{*}{ Mother's Schooling } & No schooling & 24.658 \\
\hline & $\begin{array}{l}<5 \text { years } \\
\text { completed }\end{array}$ & 19.056 \\
\hline & $\begin{array}{l}5-7 \text { years } \\
\text { completed }\end{array}$ & 19.258 \\
\hline & $\begin{array}{l}8-9 \text { years } \\
\text { completed }\end{array}$ & 19.621 \\
\hline & $\begin{array}{l}\text { 10-11 years } \\
\text { completed }\end{array}$ & 14.907 \\
\hline & $\begin{array}{l}\geq 12 \text { years } \\
\text { completed }\end{array}$ & 14.361 \\
\hline \multirow[t]{3}{*}{ Religion } & Hindu & 19.233 \\
\hline & Muslim & 16.173 \\
\hline & Others & 21.042 \\
\hline \multirow[t]{4}{*}{ Caste } & SC & 20.215 \\
\hline & ST & 21.373 \\
\hline & ОВС & 20.702 \\
\hline & Others & 14.672 \\
\hline \multirow[t]{2}{*}{ Residence } & Rural & 19.463 \\
\hline & Urban & 18.494 \\
\hline \multirow[t]{5}{*}{ Wealth index } & Poorest & 25.728 \\
\hline & Poor & 21.096 \\
\hline & Middle & 20.567 \\
\hline & Rich & 15.265 \\
\hline & Richest & 15.543 \\
\hline \multirow[t]{6}{*}{ Regions } & North & 17.619 \\
\hline & Central & 21.655 \\
\hline & East & 21.526 \\
\hline & West & 13.889 \\
\hline & South & 16.469 \\
\hline & North-East & 18.824 \\
\hline \multirow[t]{2}{*}{ Has Minimum Diet Diversity } & No & 19.953 \\
\hline & Yes & 17.518 \\
\hline \multirow{2}{*}{$\begin{array}{l}\text { Child given anything other than breastmilk } \\
\text { in the first } 3 \text { days }\end{array}$} & No & 18.135 \\
\hline & Yes & 22.393 \\
\hline \multirow{3}{*}{$\begin{array}{l}\text { Duration of exclusive breastfeeding (in } \\
\text { months) }\end{array}$} & $0-5$ & 21.862 \\
\hline & $6-11$ & 19.742 \\
\hline & $12+$ & 12.782 \\
\hline \multirow[t]{2}{*}{ Stunted } & No & 18.321 \\
\hline & Yes & 21.020 \\
\hline \multirow[t]{2}{*}{ Severely Stunted } & No & 18.783 \\
\hline & Yes & 24.486 \\
\hline \multirow[t]{2}{*}{ Anaemic } & No & 17.309 \\
\hline & Yes & 22.287 \\
\hline Total Predicted Prevalence & & 19.223 \\
\hline
\end{tabular}

$19.95 \%$ among children not having minimum diet diversity. The predicted VAD among stunted and severely stunted children is $21.02 \%$ and $24.48 \%$ respectively compared to $18.32 \%$ among non-stunted children. The predicted prevalence of VAD for anaemic children is $22.28 \%$ compared to 17.30 for non-anaemic children.

\section{Discussion}

The present study focuses on the deficiency of one of the essential micronutrients, that is, Vitamin A, among under five children utilising the national representative sample. Major states having children with 
VAD are Jharkhand, Mizoram, Madhya Pradesh, Andhra Pradesh, Telangana and Haryana. Studies conducted in South India has shown severe visual impairment, which is one of the consequences of VAD, in Andhra Pradesh. ${ }^{18}$ The VAS programme which is a bi-annual strategy programme in collaboration with UNICEF and other agencies, had been implemented in India's 15 major states. Thus, the full VAS coverage, which is 2 VAS doses per child per year, had increased from $25 \%$ in 2006 to $63 \%$ in 2012 . Out of the 15 states, 6 had reported full coverage of VAS, above $80 \%$, which included Bihar, Gujarat, Madhya Pradesh, Odisha, Rajasthan and Tamil Nadu. The supplementation programme was however implemented in different manners in different states, with varying success rates, and thus the variability in the VAD prevalence across the states, obtained from the present study. The variability of VAS had ranged from around 5\% in West Bengal to 100\% in Bihar. Jharkhand and Karnataka had zero VAS coverage, with only one round in $2012 .{ }^{19,20}$

The current study has revealed that VAD is a major nutritional deficiency affected by several socio-economic and demographic factors. It has been found that there exists a significant association with sex of the child, though the strength is not much and there is not much of difference between male and female pertaining to the prevalence of VAD. ${ }^{21}$ Age has shown to be not only a significant factor but a strong factor associated with VAD, especially for the age groups more than 36 to 48 months. In studies it has been observed that in age-groups more than 4 years not only there is prevalence of VAD, but also the children suffer from night blindness, conjunctical xerosis and bitit's spots. ${ }^{22}$ Mother's schooling years indicating the literacy of female has shown to have a significantly strong association with VAD and mostly among the mothers having no schooling. This finding has been highlighted previously in one of the Chinese studies based on. ${ }^{23}$ The association between prevalence of $\mathrm{VAD}$ and socio-economic factors has revealed a significant prevalence among the economically backward sections of the society such as among the SC/ST and OBCs, and also among children belonging to poor families. ${ }^{22,24}$

Poor dietary intake of Vitamin A rich foods or having a minimum dietary diversity, are some common causes of VAD in developing countries, mostly among young children. ${ }^{25,26}$ The present study has also revealed similar results with respect to having a minimum dietary diversity being significantly associated with VAD among under five children. Due to socio-cultural and economic factors many developing countries have low dietary intake of animal products which are rich in several micronutrients like vitamin A, iron etc. ${ }^{27,28}$ Hence, due to such reasons, India suffering from several micronutrient deficiencies are quite common. ${ }^{29}$ Studies based on Indian children showed that $50 \%$ of vitamin-A supplementation (VAS) doses are retained and this value could be utilized to reduce the risk to around 10\% among 1-3-year-old children. $^{30,31}$

Exclusive breastfeeding for a longer duration has depicted a reduction in prevalence of VAD which is also significantly associated with it. In a Bangladesh based study there were similar results showing breastfeeding causing reduction in VAD related diseases like xerophthalmia and has recommended mothers in developing countries for longer duration of breastfeeding. ${ }^{32}$ Malnutrition having a significant impact on health is a known fact from most studies, especially for under five children and thereby a leading cause of global burden of disease. Even the current study reveals significant prevalence of VAD among stunted children. ${ }^{33}$ Another important finding the study shows is the significant prevalence of VAD among anaemic children. Anaemia, stunting, poor dietary intake and VAD are interrelated factors among themselves, as shown in studies ${ }^{34}$ and Vitamin A is actually involved in the pathogenesis of anaemia with several biochemicals, diet parameters of anaemia were found to be correlated with plasma levels of retinol, thereby confirming the possible relationships between anaemia and VAD. $^{35,36}$

\section{Conclusion}

The current prevalence of VAD in India is $17.54 \%$. Socio-economic and demographic inequality exists in VAD among the children in India. Increase in mother's education and duration of breastfeeding may lower the VAD among the children. Children are required to intake food of at least minimum diet diversity. The prevalence of $\mathrm{VAD}$ is found to be more among stunted and anaemic children. The study suggests in focusing on the targeted groups of children who are at more risk in developing VAD and planning interventions for specific groups. The nutrition programs require a multisectoral approach for addressing the needs of macronutrient and micronutrient deficiencies simultaneously to enhance the current situation of nutrition among children in India.

\section{Limitations}

Being a secondary data analysis, the conclusion from this study should be interpreted with some cautions. The study is limited by the lack of real time data, and may not truly represent the present estimates as the survey was conducted during 2017-18. The cross sectional design of the survey does not allow us to establish a causal relationship between the $\mathrm{VAD}$ and the determinants used in the analysis.

\section{Funding}

There was no funding required for this study.

\section{Availability of data and materials}

Data was requested and obtained from concerned authorities.

\section{Authors' contributions}

All authors have contributed in each section of the study.

\section{Consent for publication and ethical approval}

The data source is secondary and are obtained upon request for the authorities.

\section{Declaration of competing interest}

The authors declare no conflict of interest among them.

\section{Acknowledgements}

The authors would like to acknowledge the Population Council for providing the survey dataset in order to carry out this study.

\section{References}

1 Olson JA, Sommer A, West KP. Vitamin A Deficiency: Health, Survival, and Vision. 1996.

2 Rice AL, West Jr KP, Black RE. Vitamin A Deficiency. Comparative Quantification of Health Risks: Global and Regional Burden of Disease Attributes to Selected Major Risk Factors. Geneva: World Health Organization; 2004:211-256.

3 Villamor E, Fawzi WW. Effects of vitamin a supplementation on immune responses and correlation with clinical outcomes. Clin Microbiol Rev. 2005;18(3):446-464.

4 Bates CJ. Vitamin A. The lancet. 1995;345(8941):31-35.

5 Beaton GH. Effectiveness of vitamin A supplementation in the control of young child morbidity and mortality in developing countries. United Nations Subcommittee on Nutrition (SCN) News. 1993;9:17-23.

6 UNICEF. Vitamin A Supplementation: a statistical snapshot. Retrieved from htt ps://data.unicef.org/resources/vitamin-supplementation-statistical-snapshot/; 2016. Accessed November 30, 2020.

7 UNICEF. Vitamin A deficiency. Retrieved from https://data.unicef.org/topic/nutriti on/vitamin-a-deficiency/; 2019. Accessed December 1, 2020.

8 Guideline WHO. Vitamin A Supplementation in Infants and Children 6-59 Months of Age. vol. 269. Geneva: World Health Organization; 2011:16. 
9 World Bank. World Development Report 1993: Investing in Health. vol. 1. World Bank; 1993.

10 Rahmathullah L, Underwood BA, Thulasiraj RD, et al. Reduced mortality among children in southern India receiving a small weekly dose of vitamin A. N Engl J Med. 1990;323(14):929-935.

11 Singh V, West KP. Vitamin A deficiency and xerophthalmia among school-aged children in Southeastern Asia. Eur J Clin Nutr. 2004;58(10):1342-1349.

12 Green HN, Mellanby E. Vitamin A as an anti-infective agent. Br Med J. 1928;2(3537): 691.

13 Gragnolati M, Shekar M, Das Gupta M, Bredenkamp C, Lee YK. India's Undernourished Children: A Call for Reform and Action. 2005.

14 UNICEF. UNICEF data warehouse. Retrieved from https://data.unicef.org/resource s/data_explorer/unicef_f/?ag=UNICEF\&df $=$ GLOBAL_DATAFLOW\&ver $=1.0 \& d q=$. NT_VAS_TWODOSE..\&startPeriod=2016\&endPeriod=2019; 2018. Accessed November 30, 2020 .

15 International Institute for Population Sciences (IIPS) and ICF. National Family Health Survey (NFHS-4), 2015-16: India. Mumbai: IIPS; 2017.

16 Chen W, Qian L, Shi J, Franklin M. Comparing performance between log-binomial and robust Poisson regression models for estimating risk ratios under model misspecification. BMC Med Res Methodol. 2018;18(1):1-12.

17 Comprehensive National Nutrition Survey (CNNS). CNNS National Report 2016-18. New Delhi: Ministry of Health and Family Welfare (MoHFW), Government of India, UNICEF and Population Council; 2019.

18 Krishnaiah S, Rao BS, Narasamma KL, Amit G. A survey of severe visual impairment in children attending schools for the blind in a coastal district of Andhra Pradesh in South India. Eye. 2012;26(8):1065-1070.

19 Rah JH, Houston R, Mohapatra BD, et al. A review of the vitamin A supplementation program in India: reasons for success in the states of Bihar and Odisha. Food Nutr Bull. 2014;35(2):203-210.

20 Rah JH, Kumar R, Deb S, Aguayo V. Scaling up Vitamin a Supplementation in India: Much Progress, Some Challenges. 2015.

21 Sachdeva S, Alam S, Beig FK, Khan Z, Khalique N. Determinants of vitamin A deficiency amongst children in Aligarh District, Uttar Pradesh. Indian Pediatr. 2011; 48(11):861-866.

22 Arlappa N, Balakrishna N, Laxmaiah A, et al. Prevalence of vitamin A deficiency and its determinants among the rural pre-school children of Madhya Pradesh, India. Ann Hum Biol. 2011;38(2):131-136.
23 Jingxiong J, Toschke AM, von Kries R, Koletzko B, Liangming L. Vitamin A status among children in China. Publ Health Nutr. 2006;9(8):955-960.

24 National Institute of Nutrition. National Nutrition Monitoring Bureau, Prevalence of vitamin A deficiency among preschool children in rural areas, technical report 23. Hyderabad: NIN. Retrived from https://www.nin.res.in/downloads/VAD-REPOR T-final-21Feb07.pdf; 2006.

25 Nelson KE, Williams CM, eds. Infectious Disease Epidemiology: Theory and Practice. Jones \& Bartlett Publishers; 2014.

26 West Jr KP. Dietary vitamin-A deficiency: effects on growth, infection, and mortality. Food Nutr Bull. 1991;13(2):1-12.

27 Dary O, Hurrell R. Guidelines on Food Fortification with Micronutrients. Geneva: World Health Organization, Food and Agricultural Organization of the United Nations; 2006.

28 Gonçalves A, Estevinho BN, Rocha F. Microencapsulation of vitamin A: a review. Trends Food Sci Technol. 2016;51:76-87.

29 Yip R. Significance of an abnormally low or high hemoglobin concentration during pregnancy: special consideration of iron nutrition. The American journal of clinical nutrition. 2000;72(1):272S-279S.

30 Reddy V, Sivakumar B. Studies on vitamin A absorption in children. Indian Pediatr. 1972;9:307-310.

31 Kalz F, Schafer A. Vitamin A serum levels after ingestion of different vitamin A preparations. Can Med Assoc J. 1958;79:918-919.

32 Mahalanabis D. Breast feeding and vitamin A deficiency among children attending a diarrhoea treatment centre in Bangladesh: a case-control study. Br Med J. 1991;303 (6801):493-496.

33 Ejaz MS, Latif N. Stunting and micronutrient deficiencies in malnourished children. J Pakistan Med Assoc. 2010;60(543).

34 Ahmed F, Mahmuda I, Sattar A, Akhtaruzzaman M. Anaemia and vitamin A deficiency in poor urban pregnant women of Bangladesh. Asia Pac J Clin Nutr. 2003; 12(4):460-466.

35 Semba RD, Bloem MW. The anemia of vitamin A deficiency: epidemiology and pathogenesis. Eur J Clin Nutr. 2002;56(4):271-281.

36 Majia LA, Hodges RE, Arroyave G, Viteri F, Torun B. Vitamin A deficiency and anemia in Central American children. The American journal of clinical nutrition. 1977; 30(7):1175-1184. 